\title{
Instrucciones para el cuidado de la frontera de Baja California en 1848
}

Angela Moyano

a guerra entre México y los Estados Unidos terminó en febrero de 1848, fecha en que fue firmado el tratado de paz llamado de Guadalupe-Hidalgo. El gobierno del presidente José Joaquín Herrera se preocupó entonces por resguardar la nueva frontera. Dado el sentimiento expansionista del país vecino, se preveía un nuevo choque. Además, habia que proteger a los habitantes de la región de las incursiones de los llamados "indios salvajes". En julio de 1848 se ordenó a los jefes políticos que prestaran mayor atención a la frontera recién establecida para conservar la integridad del territorio. Se restablecian las compañías presidiales y ordenaba el establecimiento de colonias militares. Se dividió el territorio fronterizo en tres partes: la de Oriente, la de Chihuahua y la de Occidente. Las futuras colonias se distribuyeron de tal manera que siete quedarian en el Oriente, cinco en Sonora y una en Baja California. Dependerían del gobierno federal y con el tiempo se convertirían en pueblos. El artículo 3o. del decreto del 19 de julio de 1848 así lo estableció:

cuando la Colonia haya progresado, de suerte que sus habitantes puedan formar un pueblo, el gobernador del Estado respectivo lo pondrá en conocimiento del supremo gobierno, solicitando lo declare así. Este lo hará en caso de que no se perjudique la defensa exterior de la república disponiendo que se traslade a un punto de inmediato para formar nueva colonia la fuerza alistada militarmente. ${ }^{1}$

La tierra de cada colonia militar se dividiría en lotes y, subsidiada por el gobierno, se daría a los soldados para que la cultivaran. Al final de un servicio de 6 años, cada soldado recibiría una bonificación de diez pesos y un lote de la tierra que había trabajado. El total de las fuerzas enviadas sería de 2426 soldados -1175 serian de caballería - ${ }^{2}$, número superior al que pretendía enviar el gobierno norteamericano. A pesar de que por medio del artículo XI del tratado de Guadalupe Hidalgo, el gobierno de los Estados Unidos había adquirido la responsabilidad de vigilar la frontera en cuanto a los ataques indigenas, para fines de 1848 sólo habían enviado 1403 soldados -ninguno dè caballería - a resguardar la región. . $^{3}$

Según el decreto de julio de 1848 cada una de las divisiones de la frontera estaría a cargo de un coronel con funciones de inspector quien

Francisco F. de la Maza, Código de colonización y terrenos baldios de la República Mexicana, México, Imprenta Ignacio Cumplido, 1893. p. 400-406, Doc. 2.

2 Fred I. Rippy, The United States and Mexico, Nueva York, A.M.S. Press, 1971. p. 77.

3 Luis G. Zorrilla, Historia de las relaciones entre México y los Estados Unidos de América, México, Ed. Porrúa, 1975, vol. I., p. 282. 
respondería directamente ante el gobierno federal. El reglamento le señalaba las funciones de comandante militar, administrador de justicia, inspector de todos los ramos -inclusive de la tesoreria - y reglamentador de la economía de la colonia. A sus órdenes estaría un subintendente y un capitán a cuyo cargo estaría el gobierno interior y el mando de las armas. A cada colonia se le asignó una fuerza militar que podría aumentarse con voluntarios. Se previó que desde el principio el gobierno adelantaría a los colonos seis meses de haberes, herramientas, arados, bueyes, caballos y lo necesario para construir sus casas.

La península de Baja California fue recuperada oficialmente por México en agosto de 1848 , dos meses después de expedido el decreto. Debido a la importancia que se concedía al trazo dé la nueva línea divisoria, el presidente Herrera pidió permiso a la Cámara de Diputados para nombrar al coronel y diputado Rafael Espinosa jefe político de la Baja. California. En un documento que acabo de localizar en el Archivo General de la Nación, se dieron a Espinosa las indicaciones geográficas que debía seguir la nueva línea divisoria y una serie de instrucciones para defender la nueva frontera; el documento data de abril de 1849 . A Espinosa se le nombró también encargado del establecimiento de la colonia militar.

En vista de la imposibilidad de ofrecer un resumen detallado de un documento que consta de catorce páginas, me limitaré a subrayar lo que juzgo más importante. En la sección dedicada a lo que se consideraba necesario para la fundación de una colonia militar en la frontera de Baja California se encuentra algo muy interesante: se pidió al señor Espinosa, jefe político, que procurase la traslación a Baja California de familias de mexicanos que no quisieran vivir en la Alta California "bajo las leyes del gobierno de los Estados Unidos". Como para ese momento ya habían empezado los despojos y abusos de los norteamericanos en contra de los mexicanos residentes en la Alta California, puede asegurarse que a Espinosa no le faltaron voluntarios que quisieran emigrar al actual estado de Baja California. Luis de la Rosa, entonces ministro de México en Washington, se quejaba de que, con el fin de que saliesen del territorio, las nuevas autoridades de Alta California embarcaban por la fuerza a los mexicanos, lo que nos confirma, dada la dificultad de transporte, que muchos de ellos se dirigieron al norte de la península. $O$ sea que el primer cambio que se dió en Baja California al convertirse en frontera fue el aumento de población.

La sección más importante del documento es indudablemente la que lleva por título "Instrucciones que se le dieron a Espinosa" y va firmada por el entonces Ministro de Relaciones, Don Luis G. Cuevas. Cito a continuación:

Dos puntos deben ocupar principalmente el celo y vigilancia del Jefe Político de California; la seguridad del territorio y su prosperidad. Esta segunda influye directamente en la primera, pues será tanto más sólida y duradera la unión de aquella península con el resto de la $\mathrm{Re}$ pública cuanto más bienes perciban de ella sus habitantes. Por lo que hace a la seguridad, el peligro que se presenta como más próximo, nace de la vecindad de la Alta California, perteneciente hoy a los Estados Unidos. La línea que ha de separar ambas posesiones, no está aún trazada sobre la tierra. En el tratado de Guadalupe se convinieron acerca de ella estos tres puntos: que ha de ser una línea recta, que ha de empezar por oriente en el punto de confluencia del Gila 
con el Colorado; que ha de terminar al poniente sobre la costa del pacífico en un punto distante tres millas o sea una legua marina de la parte más austral del puerto de San Diego... la línea divisoria según lo pactado debe ir de Este a Oeste y se recomendará mucho a los comisionados que para fijarla con claridad aprovechen siempre que se pueda los objetos naturales (como ríos o montañas) cuya dirección convenga seguir para disfrutar la ventaja de tener límites naturales e inmutables... ${ }^{4}$

A México le importaba mucho que la demarcación de la línea fuera muy bien hecha para evitar disputas futuras. Se preveia ya que en vista de los sentimientos expansionistas en California y Texas, el problema fronterizo volvería a surgir.

A continuación, el ministro Cuevas dió a Espinosa una sabia recomendación: "cuantas menos relaciones - le dijo-, cuantas menos comunicaciones haya por ahora entre nuestra California y las posesiones americanas, menos riesgo tendremos". ${ }^{5}$ Sin embargo le recomendó evitar todo motivo de queja que pudiera dar pretexto a reclamaciones. Recomendó "exacta justicia y poco trato". En otros escritos he hecho ver cómo fueron los diplomáticos mexicanos, sagaces y previsores, quienes salvaguardaron en la medida de lo posible la integridad de nuestro territorio. Lo que perdimos nos lo deben los políticos de la época. Aquí, en este documento, se aprecia la preocupación del ministro de Relaciones al encomendar al jefe político de Baja California que velase sobre la integridad del territorio.

Historiadores posteriores han calificado los años que transcurrieron de 1848 al principio de la guerra civil estadunidense, como los más peligrosos para la integridad y la existencia misma de México. Cuevas, con su gran experiencia en el trato con los norteamericanos, se daba cuenta de que el Tratado de Guadalupe-Hidalgo no habia calmado su ansia de tierra sino que habia fortalecido el sentimiento de destino manifiesto y su ambición por más territorio. De ahí su recomendación de que se observara la ley que prohibia colonias de norteamericanos en la península o la entrada de un gran número de ciudadanos de esa nacionalidad. Aún en el caso de personas aisladas, sólo debía dejarlas entrar cuando llevaran pasaporte. Tampoco se les debía permitir que adquiriesen propiedades sin previa licencia del gobierno federal. Con mucha visión, el ministro Cuevas previno que se establecerían puestos clandestinos en la costa del Pacífico y en las márgenes del río Colorado que pidió se vigilaran estrictamente: le parecía que los norteamericanos se querían apoderar del golfo de Cortés. Del lado del Pacifico habia que defender el puerto de San Miguel y la bahía de Todos Santos pues sabía que la ambicionaban. De ahí que recomendara mantener en la región una fuerza respetable para defenderla. Según el ministro, los norteamericanos tratarian paulatinamente de lograr lo que no habían podido obtener por el tratado de paz, o sea el norte de Baja California y el golfo de Cortés. No dudaba que tratarían de establecer una población en la unión del río Gila y el golfo de Cortés. "Es necesario impedirlo a toda costa", dijo, porque "tarde o temprano vendrian ellos a dominar en la costa de Sonora y en toda nuestra California."6

4 Rippy, op. cit., p. 74.

"Archivo General de la Nación, caja núm. 315, Documentos para la historia de Baja California, "Gefes Politicos" - nombramiento de Rafael Espinosa".

6 Ibid, f. 4. 
Cuevas explicó que el conservar la faja de tierra que baña el Colorado, desde donde se junta con el Gila, era uno de los puntos que más trabajo había costado en las negociaciones de paz porque dicha faja era la que unia a Baja California con Sonora y por lo tanto mantenía la continuidad del territorio nacional. En esa cuestión expresó su esperanza de que con el tiempo se fundaran poblaciones mexicanas en la región. Sugirió que una de las maneras de mantener vigilancia sobre el golfo de Cortés era propiciar el comercio entre Baja California y Sonora: por ese motivo no habia que habilitar ningún puerto de Baja California para el comercio exterior pues al insistir que todos sus productos llegaran por Sonora se insistía también en el fortalecimiento de sus relaciones con el interior del país. ${ }^{7}$ Desgraciadamente no se hizo caso a tan sa-. bia recomendación sino hasta apenas hace algunos años.

Es interesante hacer notar que Cuevas auguró que sólo el nombramiento de un obispo para la región compondría los problemas indigenas... "el mejor medio de promover la civilización de aquellas gentes, es de catequización por ministros eclesiásticos adornados de virtud y de laboriosidad". ${ }^{8}$ Pensaba que la secularización extemporánea de las misiones de 1834 había sido la causa de gravísimos daños para los indios de la región.

A través de este documento sabemos con certeza que los indios "gileños" tenian asolada la comarca, pero el ministro no recomendó la fuerza para someterlos sino que escribió a Espinosa: "La experiencia de que el gobierno español adelantó más por el medio pacífico y humano de la catequización y de las misiones debe servirnos de ejemplo". Instó a Espinosa a guardar la mayor armonía con el que fuese designado obispo de la península y con los demás ministros del culto. Siendo práctico, le pidió que acusara a aquéllos que no cumplieran con su deber. ${ }^{9}$

La parte final del documento muestra que Cuevas tenía conocimientos acerca de la economía de Baja California. Recomendó el desarrollo del cultivo de la vid y el olivo; pidió la siembra de trigo en los terrenos con agua - daba los datos pertinentes de las cosechas de trigo en años anteriores-; sugirió se reestableciera la pesca de perlas y expresó el deseo de que se fundase un establecimiento mexicano para la de la ballena. ${ }^{10}$ En ese punto ofreció la ayuda del gobierno para la formación de una empresa nacional.

La guerra había dejado al país entero en una situación de gran penuria. Dada la lejanía geográfica y económica, el estado de Baja California era uno de los más afectados. El nuevo jefe político, coronel Rafael Espinosa, llegó a la península con órdenes de cumplir el decreto sobre las colonias.. Asignó al capitán Manuel Castro como comandante militar, con el sargento José Antonio Chávez como su segundo. Llevaron además a dos sargentos, tres cabos y cuatro soldados. La colonia se organizó primero en Rosario para después cambiarla, en julio de 1849, a Santo Tomás, en el partido Norte.El cambio se hizo por juzgarse que la región era más fértil. Al principio la colonia progresó y llegó a tener - hasta doscientos miembros. Para su desgracia el capitán Castro y el teniente Chávez se convirtieron en caciques de los escasos pobladores.

José Matías Moreno, uno dé los héroes de la resistencia a la invasión norteamericana de Baja California en 1847, escribió desde San Diego al

7 Ibidem, f. 5.

8 Ibidem, f. 6.

9 Ibidem, f. 8.

10 Ibidem, f. 9. 
coronel Rafael Espinosa, radicado en La Paz. En su carta del 29 de noviembre de 1851 le hizo un historial de los acontecimientos.

Hace un año y medio que arribó a la frontera de Baja California una soldadesca al mando del capitán Don Manuel Castro y teniente Don José Antonio Chávez, con el nombre de colonia militar. Desde ese fatal ingreso, la frontera ha sido el teatro de innumerables males y de graves trascendencias, ya para los desgraciados habitantes de ese pais, y ya para el Supremo Gobierno... En el mes de agosto.de este año esperábamos en la frontera una nueva autoridad con carácter de sub-jefe político y sub-inspector de la llamada colonia, y con esto nuestras esperanzas se ensanchaban por ver remediados tantos males. En este mismo tiempo se esparcieron rumores de parte de los jefes de la colonia de que cualquiera que fuera el nuevo jefe que llegase, no seria admitido, y que con cualesquiera pretexto lo lanzaría. Para llevar a cabo tan pernicioso proyecto, el capitán Castro hizo una deserción a principios de agosto fuera del territorio mexicano, relegándose a Monterrey de la Alta California donde aún permanece, dejando el mando de la colonia al Teniente Chávez. Por fin a principios de octubre hizo su arribo a la frontera el jefe que se esperaba siéndolo el teniente coronel Don Francisco del Castillo Negrete, al que después de haberle dejado llegar a Santo Tomás todos los recursos que traía para la colonia, lo desconocieron de su autoridad lanzándolo injuriosamente bajo el pretexto frívolo de que quería introducir tropas extranjeras a la frontera. Esta, pues, continúa gobernada por un simple alcalde, inglés de nación, ebrio consuetudinario llamado Tomás Bona, y el teniente Chávez, que ambos reasumen omnimodas facultades. El capitán Castro, quien ejerce una grande influencia sobre Chávez y Bona, desde Monterrey comunica a éstos sus órdenes, las que son puntualmente obedecidas... ${ }^{11}$

La carta anterior resume estupendamente la situación de la frontera norte en el año de 1851. El fracaso de la colonia lo atribuía a los desmanes de la soldadesca y a los abusos de sus jefes. Su carta debe haber llegado a manos del coronel Espinosa al mismo tiempo que las quejas de los doscientos colonos avecinados en la colonia. Como ya hemos visto, mandó al teniente coronel Francisco Xavier del Castillo Negrete para hacerse cargo de la colonia. No lo recibieron sino que lo hicieron prisionero y lo regresaron a $\mathrm{La} \mathrm{Paz}$. Se levantaron entonces el colono Antonio Sosa y el Padre Reales en contra del abuso. Ellos también fueron enviados a La Paz.

El coronel Espinosa mandó entonces una fuerza de cien hombres de la Guardia Nacional de Todos Santos y San José a las órdenes del capitán Angulo. La expedición resultó infructuosa y la colonia se desintegró.

Ante la insistencia del gobierno del presidente Arista se volvió a enviar al teniente coronel del Castillo Negrete a restablecer la colonia de Santo Tomás. Adrián Valadés en su Historia de la Baja California cierra el punto diciendo:

pero nada le fue posible hacer, a causa del malestar que prevalecía en la frontera como consecuencia de los transtornos pasados. ${ }^{12}$

11 Ibidem, f. 11.

12 Amado Aguirre, Documentos para la historia de Baja California, México, Instituto de Investigaciones Históricas, UNAM, 1978, p. 64-65. 
En 1853 el coronel Espinosa fue reemplazado por el coronel Rebolledo. De la larga lista de su instrucciones, Espinosa sólo habia cumplido con la de instalar la colonia militar de Baja California, primero en el Rosario y luego en Santo Tomás. Pero falló en la selección equivocada de los jefes de la colonia: Manuel Castro y el teniente Chávez. Por la carta de José Matias Moreno sabemos que para finales de 1851 la colonia era un auténtico fracaso. Más aún: cuando Manuel Castro abandonó la colonia, el coronel Espinosa no tuvo la suficiente autoridad para que el teniente Chávez y sus secuaces aceptaran un nuevo jefe en la persona del coronel Francisco del Castillo Negrete.

En cuanto a la defensa del territorio, el coronel Espinosa también fracasó. Valadés dice que Espinosa no tomó en serio las noticias de la inminente invasión del filibustero Walker y "no habia tomado providencia alguna para la defensa peninsular". ${ }^{13}$ Como sabemos, Walker se apoderó de Ensenada en medio de la confusión originada por la falta de autoridades y de una colonia militar organizada que repeliese los ataques extranjeros. Pese a las instrucciones detalladas del ministro Cuevas, la frontera recién establecida en Baja California no sólo continuaba escasamente poblada sino en un estado de completo abandono por parte del jefe político a quien tanto se había recomendado su cuidado.

Las colonias militares fracasaron no sólo en Baja California sino en toda la frontera. Quizá fue por negligencia pues según el reglamento, el inspector debía visitarlas personalmente; en el caso de Baja California, el capitán Castro escribió que habian transcurrido diez meses sin que el coronel Espinosa los visitara. Sabemos que nunca lo hizo.

Quizá fue por dispersión: el gobierno de México mostró estar más ocupado en resguardar sus fronteras internas que las externas. El 26 de octubre de 1849 creó tres colonias militares en la Sierra Gorda en los estados de México, Querétaro y San Luis Potosí. Menos de dos años después y mientras las colonias militares del norte languidecian, estableció cuatro colonias en el istmo de Tehuantepec. Eso sumaba 25 colonias militares que mantener, abastecer y defender. Demasiado para los recursos del momento.

El 25 de abril de 1853 el presidente Antonio López de Santa Anna promulgó un decreto que derogó las colonias militares creando nuevamente, las compañías presidiales. ${ }^{14}$

Al fracasar las colonias militares, el territorio de la frontera quedó nuevamente abierto a los ataques indígenas y a la codicia de algunos norteamericanos. La década de 1850 sería una de continuas invasiones filibusteras.

13 Adrián Valadés, Historia de la Baja California 1850-1888, México, Instituto de Investigaciones Históricas, UNAM, 1975, p. 23.

14 Ibidem, p. 24. 